\title{
openheart Cardiovascular magnetic resonance T2* mapping for the assessment of cardiovascular events in hypertrophic cardiomyopathy
}

\author{
Mareike Gastl (10 , ${ }^{1,2,3}$ Christiane Gruner, ${ }^{1}$ Karin Labucay, ${ }^{1}$ Alexander Gotschy, ${ }^{1,2}$ \\ Jochen Von Spiczak, ${ }^{2,4}$ Malgorzata Polacin, ${ }^{4}$ Florian Boenner, ${ }^{3}$ Malte Kelm, ${ }^{3}$ \\ Frank Ruschitzka, ${ }^{1}$ Hatem Alkadhi, ${ }^{4}$ Sebastian Kozerke, ${ }^{2}$ Robert Manka ${ }^{1,2,4}$
}

To cite: Gastl M, Gruner C, Labucay K, et al. Cardiovascular magnetic resonance $\mathrm{T} 2 *$ mapping for the assessment of cardiovascular events in hypertrophic cardiomyopathy. Open Heart 2020;7:e001152. doi:10.1136/

openhrt-2019-001152

Received 7 August 2019 Revised 12 December 2019 Accepted 10 February 2020

Check for updates

(c) Author(s) (or their employer(s)) 2020. Re-use permitted under CC BY-NC. No commercial re-use. See rights and permissions. Published by BMJ.

${ }^{1}$ Department of Cardiology, University Hospital Zurich, Zurich, Switzerland ${ }^{2}$ Institute for Biomedical Engineering, University and ETH Zurich, Zurich, Switzerland ${ }^{3}$ Department of Cardiology, Pneumology and Angiology, Heinrich Heine University, Dusseldorf, Germany ${ }^{4}$ Institute of Diagnostic and Interventional Radiology, University Hospital Zurich, Zurich, Switzerland

Correspondence to Dr Mareike Gastl; mareike. gast।@med.uni-duesseldorf.de

\section{ABSTRACT}

Background Hypertrophic cardiomyopathy $(\mathrm{HCM})$ is associated with an increased risk of adverse cardiac events. Beyond classic risk factors, relative myocardial ischaemia and succeeding myocardial alterations, which can be detected using either contrast agents or parametric mapping in cardiovascular magnetic resonance (CMR) imaging, have shown an impact on outcome in HCM. CMR may help to risk stratify using parametric $\mathrm{T}^{*}$ * mapping. Therefore, the aim of the present study was to evaluate the association of $\mathrm{T}^{*}$ values or fibrosis with cardiovascular events in HCM.

Methods The relationship between $\mathrm{T}^{*}$ with supraventricular, ventricular arrhythmia or heart failure was retrospectively assessed in 91 patients with HCM referred for CMR on a 1.5T MR imaging system. Fibrosis as a reference was added to the model. Patients were subdivided into groups according to $\mathrm{T}^{*}$ value quartiles. Results 47 patients experienced an event of ventricular arrhythmia, 25 of atrial fibrillation/flutter and 17 of heart failure. $T 2^{*} \leq 28.7 \mathrm{~ms}$ yielded no association with ventricular events in the whole HCM cohort. $2^{*}$ of non-obstructive HCM showed a significant association with ventricular events in univariate analysis, but not in multivariate analysis. For the combined endpoint of arrhythmic events, there was already an association for the whole HCM cohort, but again only in univariate analyses. Fibrosis stayed the strongest predictor in all analyses. There was no association for $\mathrm{T}^{*}$ and fibrosis with heart failure.

Conclusions Decreased T2* values by CMR only provide a small association with arrhythmic events in $\mathrm{HCM}$, especially in non-obstructive HCM. No information is added for heart failure.

\section{BACKGROUND}

Hypertrophic cardiomyopathy (HCM) is a frequent cause of sudden cardiac death (SCD) ${ }^{1-3}$ Despite a common macroscopic, morphological endpoint with increasing left ventricular mass (LVM) and wall thickness, HCM is characterised by heterogeneous pathophysiological substrates. ${ }^{4}$ This

\section{Key questions}

What is already known about this subject?

- Beyond classic risk factors, relative myocardial ischaemia and succeeding myocardial alterations have shown an impact on outcome in hypertrophic cardiomyopathy (HCM). These alterations can either be detected using contrast agents or parametric mapping in cardiovascular magnetic resonance (CMR) imaging. In particular, CMR T2* mapping can detect these alterations and may help to risk stratify cardiovascular events in HCM

What does this study add?

- In this study, the relationship between $\mathrm{T}^{*}$ with supraventricular, ventricular arrhythmia or heart failure was retrospectively assessed in 91 patients with HCM referred for CMR. Fibrosis as a reference was added to the model. Decreased T2* values by CMR only provide a small association with arrhythmic events in $\mathrm{HCM}$, especially in non-obstructive $\mathrm{HCM}$ with $\mathrm{T}^{*}$ values $\leq 28.7 \mathrm{~ms}$. No information is added for heart failure.

How might this impact on clinical practice?

- Myocardial fibrosis by late gadolinium enhancement remained the strongest predictor indicating that $\mathrm{T}^{*}$ mapping may only be used in certain clinical settings. In this context, decreased T2* values by CMR may provide a small association with arrhythmic events in HCM, especially for non-obstructive HCM.

heterogeneity can be triggered by myocardial ischaemic reactions caused by a relative mismatch of myocardial demand and coronary blood supply. ${ }^{4-6}$ Over time, relative myocardial ischaemia is thought to trigger a varying degree of myocardial oedema, cell death, and fibrosis.

Although the disease may show a benign course, the ischaemic cascade in HCM shows an impact on prognosis. ${ }^{78}$ To determine the risk of future cardiovascular events, common 
risk stratification models include a variety of markers, for example, severity of LV hypertrophy (LVH) or nonsustained ventricular tachycardia $(\mathrm{nsVT}) .{ }^{4}$ Although this model has proven useful in risk stratification, it does not identify all patients with HCM at risk. Cardiovascular magnetic resonance (CMR) has emerged as a diagnostic tool for the ongoing search of additional risk factors in order to improve risk stratification ${ }^{910}$ and recent investigations have revealed relative ischaemia and fibrosis as potential predictors to cardiovascular events in HCM. $^{681112}$

CMR is able to detect myocardial alterations and relative ischaemia using contrast agent and parametric mapping. ${ }^{613-15}$ In particular, T2* mapping has proven feasibility to detect ischaemic segments in extracardiac organs but also in myocardial infarction and coronary artery disease $(\mathrm{CAD}) .{ }^{15-21}$ Reduced $\mathrm{T} 2 *$ values have been described in patients with HCM potentially triggered through relative ischaemia. ${ }^{22}$ As relative ischaemia seems to be related to a worse prognosis, the aim of this study was to assess the relation of myocardial T2* mapping by CMR with the occurrence of arrhythmia or heart failure (HF) in patients with HCM. As known prognostic markers, fibrosis and troponin $\mathrm{T}$ were taken into the model for comparison.

\section{METHODS}

The study was conducted in accordance with the Declaration of Helsinki and its later amendments. All data used for this study were acquired for clinical purposes and handled anonymously. This retrospective study had ethics committee approval of the Ethics Committee of the Canton of Zurich. Written informed consent was waived by the Institutional Review Board.

\section{Study population}

In total, 91 patients (age $49.9 \pm 16.8$ years) with HCM were retrospectively included in this study from June 2012 to May 2018. The patients were referred for clinical evaluation in our hypertrophic cardiomyopathy outpatient clinic and diagnosed with the disease according to the 2014 European Society of Cardiology (ESC) Guidelines ${ }^{4}$ with otherwise unexplained LVH and/or a maximal wall thickness $\geq 15 \mathrm{~mm}$. Forty-five patients $(49 \%)$ had an obstructive form with significant left ventricular outflow tract (LVOT) obstruction with either a resting or provocable gradient $\geq 30 \mathrm{~mm} \mathrm{Hg}$ on transthoracic echocardiography (TTE). Due to an influence of CAD on T2* values, patients with relevant $\mathrm{CAD}$, determined by invasive catheter coronary angiography or non-invasive imaging, were excluded. ${ }^{15}$ All patients with HCM underwent CMR. Clinical data were obtained by review of medical records. Patients were followed according to a specified care track with yearly ECG, blood work, TTE, Holter monitor and CMR every $3-5$ years.

\section{Diagnostic criteria for study endpoints}

Ventricular arrhythmias ranging from nsVT to SCD events and/or atrial fibrillation/flutter as well as HF were chosen as single or as a combined (arrhythmic) endpoint. Atrial fibrillation/flutter and ventricular arrhythmias were diagnosed either on resting ECG, Holter or during device interrogation. NsVTs were defined as $\geq 3$ ventricular beats at a rate $>100 \mathrm{bpm}$, sustained VT as duration of $>30 \mathrm{~s}$ and SCD events as follows: unexpected sudden collapse within 1 hour from the onset of symptoms in patients with a previous stable clinical course. ${ }^{122}{ }^{24}$ In addition, successful resuscitation from cardiac arrest or an appropriate intervention from an implantable cardioverter defibrillator (ICD) was regarded as SCD-equivalent. HF was defined as progression to New York Heart Association (NYHA) class III or IV in the absence of LVOT obstruction, left ventricular ejection fraction (LVEF) $<50 \%$ or hospitalisation due to HF complications. ${ }^{8}$

Besides $\mathrm{T}^{*}$ values and fibrosis, troponin $\mathrm{T}$ was obtained as an additional parameter during routine examination around the time of the CMR and a value $>0.014 \mathrm{ng} / \mathrm{mL}$ was considered elevated according to laboratory standards.

\section{Cardiovascular magnetic resonance}

CMR was performed on a 1.5T MRI System (Achieva, Philips) using a five-channel phased-array coil. Functional and geometric assessment was performed using balanced cine steady-state free precession (SSFP) images in standard long-axis geometries (two-chamber, threechamber and four-chamber view) as well as in short-axis orientation with full ventricular coverage from base to apex (repetition time (TR) / echo time (TE) $=3.3 / 1.6 \mathrm{~ms}$, flip angle $(\mathrm{FA})=60^{\circ}$, spatial resolution $=1.5 \times 1.5 \times 8 \mathrm{~mm}^{3}$, 50 phases, two slices per breath-hold)..$^{15}$

T2* mapping was performed using a single breathhold multiecho fast field-echo sequence in one shortaxis midventricular slice at end-diastole (six echoes with shortest interecho spacing, TR: $13 \mathrm{~ms}$, TE: $3 \mathrm{~ms}$, flip angle $35^{\circ}$, acquired spatial resolution $1.6 \times 2.8 \times 8 \mathrm{~mm}^{3}$, bandwidth $781 \mathrm{~Hz} /$ pixel). ${ }^{15}$ If applicable (glomerular filtration rate $>30 \mathrm{~mL} / \mathrm{min}$ ), gadolinium-based contrast agent (Gadovist, Bayer Healthcare) was administered at doses of $0.2 \mathrm{mmol} / \mathrm{kg}$ for late gadolinium-enhanced imaging (LGE). After $10 \mathrm{~min}$, a three-dimensional gradient spoiled turbo fast-field-echo sequence with a nonselective $180^{\circ}$ inversion pre-pulse was acquired at enddiastole with anatomical reference taken from balanced SSFP images. ${ }^{25}$

\section{Postprocessing}

Postprocessing was performed using commercial software (IntelliSpace Portal, Philips). Short-axis and longaxis slices were analysed covering maximum end-diastolic interventricular septum thickness (IVS), left ventricular indexed end-diastolic volume (LVEDVi), LVEF and indexed LVM (LVMi).

$\mathrm{T} 2 *$ sequences were postprocessed according to recent guidelines as follows: a region of interest (ROI) was manually drawn at a midventricular level using a standardised ROI size $\left(\approx 50 \mathrm{~mm}^{2}\right)$ and visually avoiding partial 


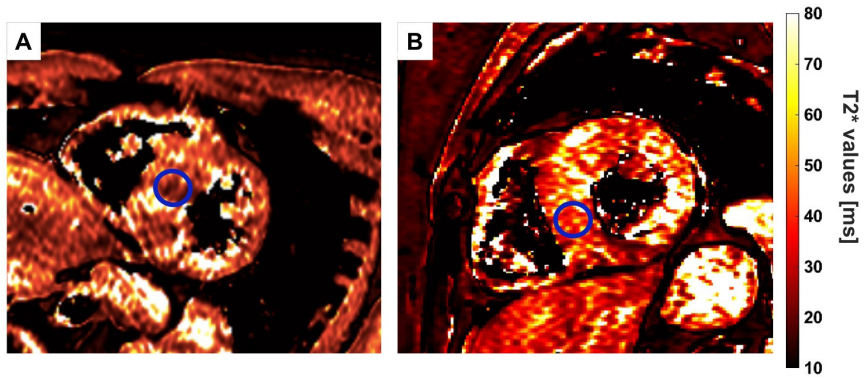

Figure 1 Placing of the $\mathrm{ROI}$ in a $\mathrm{T}^{*}$ map of a patients with $\mathrm{T}^{*}$ values below $(\mathrm{A})$ and above $(\mathrm{B})$ the fourth quartile. ROI, region of interest.

volume effects at epicardial boarders as recommended in recent guidelines (figure 1). ${ }^{20}$ This has been shown feasible in previous studies in addition to avoid susceptibility artefacts. For every ROI, the time constant of the signal intensity decay over all echoes was derived using a mono-exponential decay-curve. Afterwards, average T2* values and SD for this ROI were calculated and colourcoded using a spectral look-up table.

Fibrosis was assessed semiautomatically. Images with LGE were evaluated as follows: epicardial and endocardial contours of the short-axis LGE images in every slice were drawn manually and the amount of fibrosis as a percentage of LVMi was calculated by using a full-width at half-maximum algorithm. ${ }^{26}$

\section{Statistical analysis}

Statistical analysis was performed using SPSS (V.24.0). Unless otherwise stated, continuous variables are presented as mean $\pm \mathrm{SD}$. Normal distribution was tested using the Shapiro-Wilk test for the comparison of CMR parameters between patients with (HOCM) and without (HNCM) outflow tract obstruction. Data between the two different groups were analysed by two-sided unpaired Student t-tests for normally distributed data and MannWhitney U-test for not normally distributed data. The $\chi^{2}$ test or Fisher exact test was used to examine significant differences between nominal classifications.

In the first approach, the whole collective of patients with HCM was taken for statistical analyses. Afterwards patients were divided into HOCM and HNCM. T2* values were divided into quartiles $(\leq 25 \%, 26 \%-50 \%, 51 \%-75 \%$, $>75 \%$ ). Troponin $\mathrm{T}$ and the presence of fibrosis were entered into the model as well. To evaluate, whether T2* may predict the overall occurrence of the different arrhythmia groups or HF, univariate and multivariate binomial logistic regression models were calculated in which the event of arrhythmia or HF was entered as dependent variable and $\mathrm{T}_{2} *$ values (either below the first quartile as cut-off or below the fourth quartile as cutoff), fibrosis and troponin $\mathrm{T}$ as independent variables. The multivariate model was constructed using a forward regression model with an entrance and stay criteria of $\mathrm{p}<0.1$. For reasons of clarification, $p$ values of excluded variables are reported as well.
Table 1 Clinical (A) and CMR (B) baseline characteristics.

\begin{tabular}{|c|c|c|c|c|}
\hline \multicolumn{3}{|c|}{ (A) Clinical } & \multicolumn{2}{|c|}{ All patients $(n=91)$} \\
\hline \multicolumn{3}{|l|}{ Age (years) } & \multicolumn{2}{|l|}{$49.9 \pm 16.8$} \\
\hline \multicolumn{3}{|l|}{ Male (\%) } & \multicolumn{2}{|l|}{69 (76) } \\
\hline \multicolumn{3}{|l|}{$\mathrm{BSA}\left(\mathrm{m}^{2}\right)$} & \multicolumn{2}{|l|}{$1.92 \pm 0.2$} \\
\hline \multicolumn{3}{|c|}{ Family history of HCM, n(\%) } & \multicolumn{2}{|l|}{$32(35)$} \\
\hline \multicolumn{5}{|l|}{ Comorbidities } \\
\hline \multicolumn{3}{|c|}{ Diabetes, $\mathrm{n}(\%)$} & \multicolumn{2}{|l|}{$5(5)$} \\
\hline \multicolumn{3}{|c|}{ Hypertension, $n(\%)$} & \multicolumn{2}{|l|}{$27(30)$} \\
\hline \multicolumn{3}{|c|}{ Hypercholesterolaemia, n(\%) } & \multicolumn{2}{|l|}{$22(24)$} \\
\hline \multicolumn{3}{|c|}{$\begin{array}{l}\text { Renal insufficiency } \\
\text { (GFR <60 mL/min), } \mathrm{n}(\%)\end{array}$} & \multicolumn{2}{|l|}{$9(10)$} \\
\hline \multicolumn{3}{|c|}{ CAD, n(\%) } & \multicolumn{2}{|l|}{$0(0)$} \\
\hline \multicolumn{3}{|c|}{ Class NYHA III-IV n(\%) } & \multicolumn{2}{|l|}{$12(13)$} \\
\hline (B) CMR & All patients & HOCM & HNCM & $P$ value \\
\hline LVEF (\%) & $65.3 \pm 8.6$ & $67.0 \pm 6.5$ & $63.6 \pm 10.0$ & 0.116 \\
\hline IVS (mm) & $19.6 \pm 4.0$ & $20.9 \pm 3.6$ & $18.3 \pm 3.9$ & $<0.001$ \\
\hline LVMi $\left(g / m^{2}\right)$ & $85.0 \pm 29.6$ & $90.8 \pm 29.4$ & $79.3 \pm 29.4$ & 0.032 \\
\hline LVEDVi (mL) & $74.8 \pm 16.3$ & $75.1 \pm 14.8$ & $74.4 \pm 17.9$ & 0.520 \\
\hline $\mathrm{T} 2^{\star}(\mathrm{ms})$ & $26.5 \pm 4.6$ & $25.5 \pm 4.0$ & $27.4 \pm 4.9$ & 0.055 \\
\hline
\end{tabular}

BSA, body surface area; CAD, coronary artery diseases; CMR, cardiovascular magnetic resonance; GFR, glomerular filtration rate; $\mathrm{HCM}$, hypertrophic cardiomyopathy; $\mathrm{HNCM}$, hypertrophic non-obstructive cardiomyopathy; HOCM, hypertrophic obstructive cardiomyopathy; IVS, interventricular septum; LVEDVi, left ventricular indexed end-diastolic volume; LVEF, left ventricular ejection fraction; LVMi, left ventricular indexed mass; NYHA, New York Heart Association.

\section{RESULTS}

\section{Patient population and CMR T2*}

Clinical baseline characteristics are summarised in table 1A. The mean observation period was $1236.6 \pm 943.3$ days. Overall, 47 (49\%) patients experienced ventricular events with $3(6 \%)$ patients surviving a SCD (figure 2). Twenty-five (27\%) patients exhibited atrial fibrillation/ flutter. Seventeen patients $(19 \%)$ presented with HF of which $3(3 \%)$ had an LVEF <50\%, $3(3 \%)$ were hospitalised due to HF complications and $11(12 \%)$ progressed into NYHA class III.

CMR characteristics of all HCM are summarised in table 1B. According to quartile analyses, 23 patients presented with a T2* value $\leq 23.3 \mathrm{~ms}$ (first quartile), 23 patients presented with $\mathrm{T} 2 *$ values between 23.4 and $26.2 \mathrm{~ms}$ (second quartile), 23 patients presented with T2* values between 26.3 and $28.7 \mathrm{~ms}$ (third quartile) and 22 patients presented with T2* values $>28.7$ ms (fourth quartile) (exemplary maps in figure 1$)$. Troponin $\mathrm{T}$ was elevated in 33 (36\%, 9 values missing) patients and fibrosis was present in $66(73 \%)$ of all CMR analyses. Fibrosis extent ranged from $1 \%$ to $38 \%$ (mean: $10.1 \% \pm 9.2 \%$ ).

\section{Ventricular arrhythmia}

The incidence of ventricular arrhythmia in the different quartiles of HCM is summarised in table 2. 


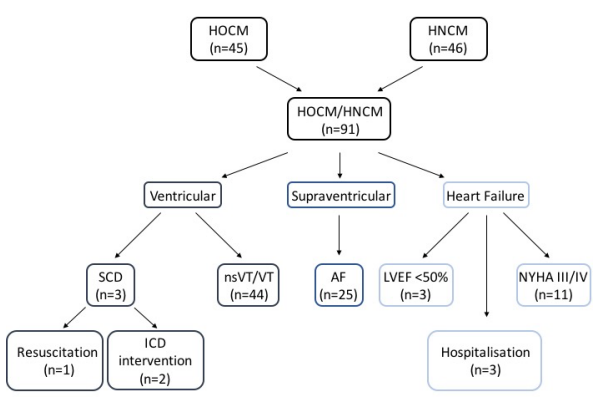

Figure 2 Study diagram with numbers indicating the occurrence of ventricular, supraventricular events and heart failure. AF, atrial fibrillation/flutter; $\mathrm{HNCM}$, hypertrophic non-obstructive cardiomyopathy; HOCM, hypertrophic obstructive cardiomyopathy; ICD, implantable cardioverter defibrillator; LVEF, left ventricularejection fraction; nsVT, nonsustained ventricular tachycardia; NYHA, New York Heart Association; SCD, sudden cardiac death; VT, ventricular fibrillation/tachycardia.

In univariate binomial regression calculations independent from the onset of ventricular arrhythmia, only fibrosis and troponin $\mathrm{T}$, but not $\mathrm{T} 2 *$, were associated with an increased risk of arrhythmia (table 3A). In multivariate analysis, fibrosis stayed the only independent predictor $(\mathrm{p}=0.004, \mathrm{OR}=5.29)$.

In a second approach, patients were divided into HOCM and HCM. According to the ESC Guidelines on HCM, 45 patients (49\%) had a diagnosis of HOCM. ${ }^{4}$ There was no significant difference in T2* values between both groups (table 1B).

Binomial regression showed that patients with HNCM with a $\mathrm{T} 2 * \leq 28.7(\mathrm{p}=0.033)$ or fibrosis $(\mathrm{p}=0.014)$ had the greatest association with ventricular events (table 3B). Fibrosis stayed the only independent predictor in multivariate analyses $(\mathrm{p}=0.039, \mathrm{OR}=10.2)$.

For HOCM, neither $\mathrm{T}^{*}$, fibrosis nor troponin $\mathrm{T}$ revealed a significant association with ventricular arrhythmias.

\section{Atrial fibrillation/flutter}

The incidence and number of included patients into the subanalyses of atrial fibrillation/flutter are summarised in table 2. Neither the whole cohort, nor the division into HNCM or HOCM revealed a significant association between $\mathrm{T} 2 *$ values, fibrosis, troponin $\mathrm{T}$ and atrial fibrillation/flutter in regression analyses.
Table 3 Results for the binomial logistic regression analysis of the relation between $\mathrm{T} 2^{*}$, troponin $\mathrm{T}$, fibrosis and ventricular events/SCD in the group of $\mathrm{HCM}(\mathrm{A})$ as well as in the subgroup of HNCM (B)

\begin{tabular}{|c|c|c|c|c|}
\hline $\begin{array}{l}\text { Ventricular } \\
\text { events }\end{array}$ & Univariate & & Multivariat & \\
\hline (A) Covariates & $\begin{array}{l}\text { OR } \\
(95 \% \mathrm{Cl})\end{array}$ & $P$ values & $\begin{array}{l}\text { OR } \\
(95 \% \mathrm{Cl})\end{array}$ & $P$ values \\
\hline $\begin{array}{l}\text { Cardiac } \\
T 2^{*} \leq 23.3 \mathrm{~ms}\end{array}$ & $\begin{array}{l}1.3 \\
(0.5 \text { to } 3.4)\end{array}$ & 0.589 & - & 0.770 \\
\hline $\begin{array}{l}\text { Cardiac } \\
\mathrm{T}^{*} \leq 28.7 \mathrm{~ms}\end{array}$ & $\begin{array}{l}2.28 \\
\text { (0.8 to 6.1) }\end{array}$ & 0.104 & - & 0.721 \\
\hline Fibrosis & $\begin{array}{l}5.19 \\
(1.8 \text { to } 14.8)\end{array}$ & 0.002 & $\begin{array}{l}5.29 \\
(1.7 \text { to } 16.4)\end{array}$ & 0.004 \\
\hline Troponin T & $\begin{array}{l}2.67 \\
\text { (1.1 to } 6.7 \text { ) }\end{array}$ & 0.036 & - & 0.102 \\
\hline (B) Covariates & $\begin{array}{l}\text { OR } \\
(95 \% \mathrm{Cl})\end{array}$ & P values & $\begin{array}{l}\text { OR } \\
(95 \% \mathrm{Cl})\end{array}$ & $P$ values \\
\hline $\begin{array}{l}\text { Cardiac } \\
\mathrm{T}^{\star} \leq 23.3 \mathrm{~ms}\end{array}$ & $\begin{array}{l}4.59 \\
\text { (0.8 to 25.2) }\end{array}$ & 0.079 & - & 0.463 \\
\hline $\begin{array}{l}\text { Cardiac } \\
\mathrm{T} 2^{\star} \leq 28.7 \mathrm{~ms}\end{array}$ & $\begin{array}{l}3.35 \\
(1.1 \text { to } 16.9)\end{array}$ & 0.033 & - & 0.698 \\
\hline Fibrosis & $\begin{array}{l}8.08 \\
(1.5 \text { to } 42.8)\end{array}$ & 0.014 & $\begin{array}{l}10.2 \\
\text { (1.1 to } 93.3)\end{array}$ & 0.039 \\
\hline Troponin T & $\begin{array}{l}3.5 \\
(0.9 \text { to } 13.0)\end{array}$ & 0.061 & - & 0.210 \\
\hline
\end{tabular}

HCM, hypertrophic cardiomyopathy; HNCM, hypertrophic nonobstructive cardiomyopathy; SCD, sudden cardiac death.

\section{Combined arrhythmic endpoint}

For a combined endpoint of ventricular and supraventricular events, univariate binomial logistic regression calculations revealed an association of $\mathrm{T} 2 * \leq 28.7$ ms $(p=0.047)$ or fibrosis $(p=0.007)$ with an increased risk of arrhythmia (table 4A). In multivariate analysis, fibrosis stayed the only independent predictor $(\mathrm{p}=0.015$, $\mathrm{OR}=3.59$ ).

Dividing the whole cohort according to HOCM and HNCM, binomial regression showed that patients with HNCM with a T2* $\leq 28.7(\mathrm{p}=0.032)$ or fibrosis $(\mathrm{p}=0.016)$ had the greatest association with arrhythmic events (table 4b). However, fibrosis stayed the only predictor in multivariate analyses $(\mathrm{p}=0.052, \mathrm{OR}=5.73)$.

For HOCM, no parameter revealed a significant association with the combined endpoint of arrhythmia.

Table 2 Incidence of endpoints divided into the quartiles of T2* values

\begin{tabular}{|c|c|c|c|c|c|}
\hline & $\begin{array}{l}\text { First quartile } \\
\leq 23.3 \mathrm{~ms}\end{array}$ & $\begin{array}{l}\text { Second quartile } \\
23.4-26.2 \mathrm{~ms}\end{array}$ & $\begin{array}{l}\text { Third quartile } \\
26.3-28.7 \mathrm{~ms}\end{array}$ & $\begin{array}{l}\text { Fourth quartile } \\
>28.7 \mathrm{~ms}\end{array}$ & $P$ value \\
\hline All VT/NF/SCD, $\mathrm{n}(\%)$ & $13 / 23(57)$ & $12 / 23(52)$ & $14 / 23(61)$ & $8 / 22(36)$ & 0.38 \\
\hline All AF, n(\%) & $6 / 23(27)$ & $7 / 23(30)$ & 8/23 (35) & 4/22 (18) & 0.64 \\
\hline $\mathrm{HF}, \mathrm{n}(\%)$ & $3 / 23(13)$ & $1 / 23(4)$ & $8 / 23(35)$ & $5 / 22(23)$ & 0.05 \\
\hline
\end{tabular}

AF, atrial fibrillation/flutter; HF, heart failure; SCD, sudden cardiac death; VF, ventricular fibrillation; VT, ventricular tachycardia. 
Table 4 Results for the binomial regression analyses of the relation between $\mathrm{T} 2{ }^{*}$, troponin $\mathrm{T}$, fibrosis and ventricular events/atrial fibrillation/flutter as combined endpoint in the group of HCM (A) as well as in the subgroup of HNCM (B)

\begin{tabular}{|c|c|c|c|c|}
\hline $\begin{array}{l}\text { Combined } \\
\text { endpoint }\end{array}$ & Univariate & & Multivariat & \\
\hline (A) Covariates & $\begin{array}{l}\text { OR } \\
(95 \% \mathrm{Cl})\end{array}$ & P values & $\begin{array}{l}\text { OR } \\
\text { (95\% Cl) }\end{array}$ & $P$ values \\
\hline $\begin{array}{l}\text { Cardiac } \\
\mathrm{T}^{*} \leq 23.3 \mathrm{~ms}\end{array}$ & $\begin{array}{l}1.09 \\
\text { (0.4 to 2.9) }\end{array}$ & 0.863 & - & 0.499 \\
\hline $\begin{array}{l}\text { Cardiac } \\
\mathrm{T} 2^{*} \leq 28.7 \mathrm{~ms}\end{array}$ & $\begin{array}{l}2.71 \\
\text { (1.0 to } 7.2 \text { ) }\end{array}$ & 0.047 & - & 0.330 \\
\hline Fibrosis & $\begin{array}{l}3.81 \\
(1.4 \text { to } 10.0)\end{array}$ & 0.007 & $\begin{array}{l}3.59 \\
\text { (1.3 to 10.1) }\end{array}$ & 0.015 \\
\hline Troponin T & $\begin{array}{l}1.50 \\
(0.6 \text { to } 3.8)\end{array}$ & 0.387 & - & 0.688 \\
\hline (B) Covariates & $\begin{array}{l}\text { OR } \\
(95 \% \mathrm{Cl})\end{array}$ & $P$ values & $\begin{array}{l}\text { OR } \\
(95 \% \mathrm{Cl})\end{array}$ & $P$ values \\
\hline $\begin{array}{l}\text { Cardiac } \\
\mathrm{T}^{*} \leq 23.3 \mathrm{~ms}\end{array}$ & $\begin{array}{l}3.32 \\
(0.6 \text { to 18.1) }\end{array}$ & 0.167 & - & 0.71 \\
\hline $\begin{array}{l}\text { Cardiac } \\
\mathrm{T}^{*} \leq 28.7 \mathrm{~ms}\end{array}$ & $\begin{array}{l}4.20 \\
\text { (1.1 to } 15.6)\end{array}$ & 0.032 & - & 0.541 \\
\hline Fibrosis & $\begin{array}{l}6.27 \\
\text { (1.4 to 27.9) }\end{array}$ & 0.016 & $\begin{array}{l}5.73 \\
\text { (1.0 to } 33.2)\end{array}$ & 0.052 \\
\hline Troponin T & $\begin{array}{l}2.0 \\
(0.6 \text { to } 7.3 \text { ) }\end{array}$ & 0.292 & - & 0.672 \\
\hline
\end{tabular}

HCM, hypertrophic cardiomyopathy; HOCM, hypertrophic cardiomyopathy.

\section{Heart failure}

The incidence of HF in the different quartiles of HCM is summarised in table 2. Although a significant difference between the T2* quartile groups was indicated, no significant influence of $\mathrm{T}^{*}$, fibrosis or troponin $\mathrm{T}$ in the whole cohort as well as divided according to $\mathrm{HOCM} / \mathrm{HNCM}$ could be detected (table 5).

Table 5 Results in the whole group of HCM for the binomial regression analyses of the relation between $\mathrm{T} 2$, troponin $\mathrm{T}$, fibrosis and heart failure

\begin{tabular}{|c|c|c|c|c|}
\hline $\begin{array}{l}\text { Heart } \\
\text { failure }\end{array}$ & Univariate & & Multivari & \\
\hline Covariates & $\begin{array}{l}\text { OR } \\
(95 \% \mathrm{Cl})\end{array}$ & $P$ values & $\begin{array}{l}\text { OR } \\
(95 \% \mathrm{Cl})\end{array}$ & $P$ values \\
\hline $\begin{array}{l}\text { Cardiac T2* } \\
\leq 23.3 \mathrm{~ms}\end{array}$ & $\begin{array}{l}0.58 \\
(0.2 \text { to 2.2) }\end{array}$ & 0.426 & - & 0.217 \\
\hline $\begin{array}{l}\text { Cardiac T2* } \\
\leq 28.7 \mathrm{~ms}\end{array}$ & $\begin{array}{l}0.72 \\
(0.2 \text { to } 2.3)\end{array}$ & 0.577 & - & 0.476 \\
\hline Fibrosis & $\begin{array}{l}1.29 \\
(0.4 \text { to } 4.4)\end{array}$ & 0.687 & - & 0.950 \\
\hline Troponin T & $\begin{array}{l}2.25 \\
\text { (0.7 to } 6.8)\end{array}$ & 0.151 & - & 0.146 \\
\hline
\end{tabular}

HCM, hypertrophic cardiomyopathy.

\section{DISCUSSION}

Although commonly used for predicting adverse cardiovascular events, current risk stratification models for HCM using a combination of clinical and imaging parameters are limited in identifying all patients, mainly as a result of the heterogeneity of the disease. ${ }^{312} 27$ As adverse events may occur in patients with HCM that are considered at low risk, there is a need to identify additional markers. ${ }^{2}$

CMR is recommended a class IB indication in patients with HCM and interest has emerged to improve risk stratification models using CMR parameters. ${ }^{4}$ In this context, one focus has been on the cascade of myocardial ischaemic reactions. The presence of relative ischaemia has already shown to influence the prognosis of patients with HCM on either arrhythmic events or $\mathrm{HF}^{8}{ }^{28}$ In CMR, myocardial ischaemia and fibrosis can be imaged using contrast agents or using parametric mapping on the basis of magnetic relaxation properties. ${ }^{1429}$ In particular, T2* mapping is able to characterise the relaxation of the transverse magnetisation that is influenced by macroscopic (inhomogeneities of the magnetic field) and mesoscopic (structure of the tissue) magnetic field inhomogeneities. ${ }^{14} 20$ In this context, reduced $\mathrm{T} 2 *$ values have already shown the potential to describe structural alterations suggestive of ischaemic alterations, collagen areas or haemorrhage in cardiac and extracardiac tissues. ${ }^{15} 1821$ According to this, histopathological substrates of $\mathrm{T} 2 *$ and a correlation of $\mathrm{T} 2 *$ to flow analyses have been studied. ${ }^{16171920}{ }^{30}$ Recently, reduced T2* values have been described in a group of patients with HCM potentially triggered through relative ischaemia. ${ }^{22}$ Another explanation for the reduction of T2* values could be that in areas of reduced perfusion, oxymyoglobin and haemoglobin as oxygen suppliers are decreased, whereas deoxymyoglobin and haemoglobin are increased. In contrast to oxygenated proteins, deoxygenated proteins are paramagnetic and reduce local T2* values. However, further studies will have to confirm the potential substrates for a $\mathrm{T} 2 *$ reduction.

In the present study, patients with HCM showed a varying degree of myocardial $\mathrm{T} 2 *$ values, which supports previous studies that showed heterogeneity in myocardial ischaemic reactions. ${ }^{12}$ Therefore, individual cut-offs to predict arrhythmic events could be chosen according to quartiles. T2* mapping in the present study was not designed to detect myocardial iron overload that can further decrease $\mathrm{T} 2 *$-values with an impact on the prognosis of patients with thalassemia major. No further division below 23.4 ms was made. ${ }^{31}$

Only the endpoint of ventricular arrhythmia alone was associated with T2* values in patients with HNCM in univariate analyses. Combining arrhythmic events, there was an association between $\mathrm{T} 2 *$ and arrhythmic events of the whole HCM cohort. None could be detected for HF. Assuming T2* values to be influenced by relative ischaemia, previous studies have already detected an association of abnormal T2 
signal as a sign for myocardial damage and arrhythmia. ${ }^{32}$ In general, the results of the additional parameter of fibrosis were in line with previous studies showing an increased risk of events for patients with fibrosis. ${ }^{128}{ }^{34}$ One should note that fibrosis, which was measured covering the whole heart, stayed the strongest predictor for arrhythmic events in patients with HCM throughout univariate and multivariate analyses. Whole heart coverage using T2* is not recommended in recent guidelines due to susceptibility artefacts at the epicardial borders of the heart. ${ }^{20}$ As $\mathrm{T} 2 *$ has shown reduced values in patients with HCM and fibrosis, current analyses of the association of $\mathrm{T} 2 *$ with cardiac events in HCM possibly support results for fibrosis without the need for contrast agent, but with less clear results. This is further supported that $\mathrm{T}^{*}$ and fibrosis showed no linear correlation. Therefore, $\mathrm{T}^{*}$ values may be of potential value in cases of doubt or when patients with HCM are not eligible for contrast administration.

Especially patients with HNCM exhibited an association between $\mathrm{T}_{2} *$ values and ventricular arrhythmia or a combined endpoint, but only in univariate analyses. Taking conventional risk stratification models that include LV wall thickness and LVOT gradient, those patients would have been graded to be at lower risk. ${ }^{4}$ However, the overall significance could have been hampered due to low numbers in the subgroups.

Comparing the patients below the third quartile in common risk stratification parameters, one should note that thickened IVS and HOCM occurrence were significantly higher in patients with reduced $\mathrm{T} 2 *$ values. However, $\mathrm{T}_{2}^{*}$ values did not show a correlation to thickened IVS, elevated LVMi or age. As a consequence, $\mathrm{T} 2 *$ may potentially identify additional patients with a higher risk of arrhythmia that were considered at low risk for cardiac events using previous risk model estimations. ${ }^{45}$ It should be noted that higher $\mathrm{T} 2 *$ values do not preclude future cardiac events, suggesting further influencing factors that should be taken into account. ${ }^{8}$

The study was conducted as a retrospective, singlecentre study. Therefore, the size of our study population, especially in subanalyses, must be acknowledged as one limitation and was the reason to only perform logistic regression. Prospective multicentre studies using longer follow-up periods and more patients should be used to further evaluate the influence of $\mathrm{T} 2 *$.

Owing to our study design, patients with ICD or confirmed CAD had to be excluded, thereby potentially introducing some study bias.

Finally, LGE was not further subdivided according to the extent in \% of affected LVMi as those data have already been published before. ${ }^{12}$

Perfusion sequences and parametric $\mathrm{T} 1 *$ mapping with extracellular volume measurements would have been of additional value to quantify relative ischaemia without the use of contrast agents. Nevertheless, LGE remains still one of the gold standards for the detection of fibrosis.

\section{CONCLUSIONS}

Decreased $\mathrm{T}^{*}$ values by CMR only provide a small association with arrhythmic events in HCM, especially for HNCM. However, within most analyses, myocardial fibrosis by LGE remained the strongest predictor indicating that $\mathrm{T}^{*}$ may be used as additional marker in certain clinical settings.

Acknowledgements The authors acknowledge the support of staff at the Department of Cardiology, University Heart Center, and Institute of Diagnostic and Interventional Radiology, University Hospital Zurich.

Contributors MG, AG, JVS, MP: acquired the CMR data. MG: performed statistical analyses. CG, KL: contributed in statistical analyses. MG and RM: wrote the main manuscript. CG, KL, AG, JVS, MP, FB, MK, FR, HA, SK: contributed in discussions. All authors reviewed the manuscript.

Funding This work was supported by a grant from the German Research Foundation (DFG) Research Fellowship (GA 2621/1-1).

Competing interests None declared.

Patient consent for publication Not required.

Ethics approval Written informed consent was waived by the Institutional Review Board.

Provenance and peer review Not commissioned; externally peer reviewed.

Data availability statement Data are available upon reasonable request. All data used in this manuscript can be made available upon reasonable request from the first or last author. If made available, data will be deidentified.

Open access This is an open access article distributed in accordance with the Creative Commons Attribution Non Commercial (CC BY-NC 4.0) license, which permits others to distribute, remix, adapt, build upon this work non-commercially, and license their derivative works on different terms, provided the original work is properly cited, appropriate credit is given, any changes made indicated, and the use is non-commercial. See: http://creativecommons.org/licenses/by-nc/4.0/.

ORCID iD

Mareike Gastl http://orcid.org/0000-0002-7854-8418

\section{REFERENCES}

1 Maron BJ, Gardin JM, Flack JM, et al. Prevalence of hypertrophic cardiomyopathy in a general population of young adults. echocardiographic analysis of 4111 subjects in the cardia study. coronary artery risk development in (young) adults. Circulation 1995;92:785-9.

2 Maron BJ. Contemporary insights and strategies for risk stratification and prevention of sudden death in hypertrophic cardiomyopathy. Circulation 2010;121:445-56.

3 Elliott PM, Poloniecki J, Dickie S, et al. Sudden death in hypertrophic cardiomyopathy: identification of high risk patients. J Am Coll Cardiol 2000;36:2212-8.

4 Elliott PM, Anastasakis A, Borger MA, et al. 2014 ESC guidelines on diagnosis and management of hypertrophic cardiomyopathy: the task force for the diagnosis and management of hypertrophic cardiomyopathy of the European Society of cardiology (ESC). Eur Heart J 2014;35:2733-79.

5 Maron BJ. Hypertrophic cardiomyopathy: a systematic review. JAMA 2002;287:1308-20.

6 Ismail TF, Hsu L-Y, Greve AM, et al. Coronary microvascular ischemia in hypertrophic cardiomyopathy - a pixel-wise quantitative cardiovascular magnetic resonance perfusion study. J Cardiovasc Magn Reson 2014;16:49.

7 Maron BJ, Olivotto I, Spirito P, et al. Epidemiology of hypertrophic cardiomyopathy-related death: revisited in a large non-referral-based patient population. Circulation 2000;102:858-64.

8 Cecchi F, Olivotto I, Gistri R, et al. Coronary microvascular dysfunction and prognosis in hypertrophic cardiomyopathy. N Engl J Med 2003;349:1027-35.

9 Bongioanni S, Spirito P, Masi AS, et al. Extensive myocardial fibrosis in a patient with hypertrophic cardiomyopathy and ventricular tachycardia without traditional high-risk features. Circ Cardiovasc Imaging 2009;2:349-50.

10 Maron BJ, Maron MS, Lesser JR, et al. Sudden cardiac arrest in hypertrophic cardiomyopathy in the absence of conventional criteria for high risk status. Am J Cardiol 2008;101:544-7. 
11 Cardim N, Galderisi M, Edvardsen T, et al. Role of multimodality cardiac imaging in the management of patients with hypertrophic cardiomyopathy: an expert consensus of the European association of cardiovascular imaging endorsed by the Saudi heart association. Eur Heart J Cardiovasc Imaging 2015;16:280.

12 Chan $\mathrm{RH}$, Maron BJ, Olivotto I, et al. Prognostic value of quantitative contrast-enhanced cardiovascular magnetic resonance for the evaluation of sudden death risk in patients with hypertrophic cardiomyopathy. Circulation 2014;130:484-95.

13 Petersen SE, Jerosch-Herold M, Hudsmith LE, et al. Evidence for microvascular dysfunction in hypertrophic cardiomyopathy: new insights from multiparametric magnetic resonance imaging. Circulation 2007;115:2418-25.

14 van Oorschot JWM, Gho JMIH, van Hout GPJ, et al. Endogenous contrast MRI of cardiac fibrosis: beyond late gadolinium enhancement. J Magn Reson Imaging 2015;41:1181-9.

15 Manka R, Paetsch I, Schnackenburg B, et al. Bold cardiovascular magnetic resonance at 3.0 Tesla in myocardial ischemia. $J$ Cardiovasc Magn Reson 2010;12:54.

16 van Nierop BJ, Bax NAM, Nelissen JL, et al. Assessment of myocardial fibrosis in mice using a $\mathrm{T} 2^{*}$-weighted $3 \mathrm{D}$ radial magnetic resonance imaging sequence. PLoS One 2015;10:e0129899.

17 Huang S-Y, Li X-H, Huang L, et al. T2* mapping to characterize intestinal fibrosis in Crohn's disease. J Magn Reson Imaging 2018;48:829-36.

18 Jahnke C, Gebker R, Manka R, et al. Navigator-gated 3D blood oxygen level-dependent CMR at 3.0-T for detection of stressinduced myocardial ischemic reactions. JACC Cardiovasc Imaging 2010;3:375-84.

19 Zia MI, Ghugre NR, Connelly KA, et al. Characterizing myocardial edema and hemorrhage using quantitative T2 and T2* mapping at multiple time intervals post ST-segment elevation myocardial infarction. Circ Cardiovasc Imaging 2012;5:566-72.

20 Messroghli DR, Moon JC, Ferreira VM, et al. Clinica recommendations for cardiovascular magnetic resonance mapping of T1, T2, T2* and extracellular volume: a consensus statement by the Society for cardiovascular magnetic resonance (SCMR) endorsed by the European association for cardiovascular imaging (EACVI). J Cardiovasc Magn Reson 2017;19:75.

21 Jahnke C, Manka R, Kozerke S, et al. Cardiovascular magnetic resonance profiling of coronary atherosclerosis: vessel wall remodelling and related myocardial blood flow alterations. Eur Heart $J$ Cardiovasc Imaging 2014;15:1400-10.

22 Gastl M, Gotschy A, von Spiczak J, et al. Cardiovascular magnetic resonance T2* mapping for structural alterations in hypertrophic cardiomyopathy. Eur J Radiol Open 2019;6:78-84.

23 Priori SG, Blomström-Lundqvist C, Mazzanti A, et al. 2015 ESC guidelines for the management of patients with ventricular arrhythmias and the prevention of sudden cardiac death: the task force for the management of patients with ventricular arrhythmias and the prevention of sudden cardiac death of the European Society of cardiology (ESC). endorsed by: association for European paediatric and congenital cardiology (AEPC). Eur Heart $J$ 2015;36:2793-867

24 Buxton AE, Calkins H, Callans DJ, et al. ACC/AHA/HRS 2006 key data elements and definitions for electrophysiological studies and procedures. J Am Coll Cardiol 2006;48:2360-96.

25 Morsbach F, Gordic S, Gruner C, et al. Quantitative comparison of $2 \mathrm{D}$ and $3 \mathrm{D}$ late gadolinium enhancement MR imaging in patients with Fabry disease and hypertrophic cardiomyopathy. Int J Cardiol 2016;217:167-73.

26 Amado LC, Gerber BL, Gupta SN, et al. Accurate and objective infarct sizing by contrast-enhanced magnetic resonance imaging in a canine myocardial infarction model. J Am Coll Cardiol 2004;44:2383-9.

27 Maron MS, Maron BJ, Harrigan C, et al. Hypertrophic cardiomyopathy phenotype revisited after 50 years with cardiovascular magnetic resonance. J Am Coll Cardiol 2009;54:220-8.

28 Green JJ, Berger JS, Kramer CM, et al. Prognostic value of late gadolinium enhancement in clinical outcomes for hypertrophic cardiomyopathy. JACC Cardiovasc Imaging 2012;5:370-7.

29 Małek Łukasz A, Werys K, Kłopotowski M, et al. Native T1-mapping for non-contrast assessment of myocardial fibrosis in patients with hypertrophic cardiomyopathy--comparison with late enhancement quantification. Magn Reson Imaging 2015;33:718-24.

30 Aguor ENE, Arslan F, van de Kolk CWA, et al. Quantitative T 2* assessment of acute and chronic myocardial ischemia/reperfusion injury in mice. MAGMA 2012;25:369-79.

31 Kirk P, Roughton M, Porter JB, et al. Cardiac T2* magnetic resonance for prediction of cardiac complications in thalassemia major. Circulation 2009;120:1961-8.

32 Todiere G, Pisciella L, Barison A, et al. Abnormal T2-STIR magnetic resonance in hypertrophic cardiomyopathy: a marker of advanced disease and electrical myocardial instability. PLoS One 2014;9:e111366

33 Hen $\mathrm{Y}$, Takara A, Iguchi N, et al. High signal intensity on T2-weighted cardiovascular magnetic resonance imaging predicts life-threatening arrhythmic events in hypertrophic cardiomyopathy patients. Circ $J$ 2018;82:1062-9.

34 Kubo T, Kitaoka H, Yamanaka S, et al. Significance of high-sensitivity cardiac troponin T in hypertrophic cardiomyopathy. J Am Coll Cardiol 2013:62:1252-9.

35 Maron BJ, Spirito P, Shen W-K, et al. Implantable cardioverterdefibrillators and prevention of sudden cardiac death in hypertrophic cardiomyopathy. JAMA 2007;298:405-12. 